\title{
COMPARISON OF PHENOLIC ACIDS AND ANTIOXIDANT ACTIVITIES OF YOUNG AND MATURE LEAVES OF TECTONA GRANDIS L F
}

\author{
GREESHMA MURUKAN, MURUGAN K* \\ Department of Botany, Plant Biochemistry \& Molecular Biology Lab, University College, Thiruvananthapuram, Kerala, India. \\ Email: harimurukan@gmail.com
}

Received: 27 April 2017, Revised and Accepted: 26 September 2017

\section{ABSTRACT}

Objective: The present study aims in comparison of phenolic acids and its antioxidant potentialities of young and mature leaf extract of Tectona grandis $\mathrm{L} \mathrm{f}$.

Methods: Various phenolic acids present in methanolic leaf extract of young and mature leaves of T. grandis were analyzed by reversed-phase highperformance liquid chromatography analysis. The antioxidant potentiality of the extracts was determined by various analytical methods such as 2,2-diphenyl-1-picrylhydrazyl, ferric reducing/antioxidant power, and metal chelating activity.

Results: Methanolic leaf extracts of young and mature leaf of T. grandis showed a pool of phenolic compounds such as gallic, vanillic, p-hydroxybenzoic, ferulic, chlorogenic, sinapic, p-coumarate, and cinnamic acids. Irrespective of the methods used for analyzing antioxidant capacity, young leaf extract showed potent antioxidant potentiality when compared with the mature leaf extract.

Conclusion: The methanolic extract of teak leaves is rich source of many phenolic compounds, and these compounds attribute to the antioxidant capacity of the leaves. Meanwhile, by comparing the young and mature leaves, the young leaves showed much more potential than the other. It is, therefore, concluded that the young teak leaves can be used as a good source of natural antioxidant.

Keywords: Tectona grandis L f., Phenolic acids, Reversed-phase high-performance liquid chromatography, Antioxidant, 2,2-diphenyl-1-picrylhydrazyl, Ferric reducing/antioxidant power, Metal chelating activity.

(C) 2018 The Authors. Published by Innovare Academic Sciences Pvt Ltd. This is an open access article under the CC BY license (http://creativecommons. org/licenses/by/4. 0/) DOI: http://dx.doi.org/10.22159/ajpcr.2018.v11i1.19430

\section{INTRODUCTION}

Polyphenols are widely distributed in plants kingdom and also forms the major ingredient in the human diet. Phenolics are involved in many functions such as defense and stress tolerance [1]. As they are ubiquitous in plant species, their distribution in the plant tissues is either as insoluble phenolics along in cell wall or as the soluble phenolics within the vacuole. The biological properties of polyphenols and their health benefits are of the prime area of research including its extraction, separation, and identification of the fractions from natural sources. Many studies were focussed on the antioxidant activities of phenolic compounds in scavenging and free radical species [2].

Phenolics are aromatic ring bearing molecules with one or more hydroxyl groups and their structures ranges from simple to complex high-molecular-weight polymers. They are widespread groups of substances in flowering plants, occurring in all vegetative organs, as well as in flowers, fruits, vegetables, cereals, grains, seeds, and drinks. In general, referred to as polyphenols, they are secondary metabolites which are derived from pentose phosphate, shikimate, and phenylpropanoid pathways in plants.

Phenolic acids consist of two subgroups: The hydroxybenzoic and hydroxycinnamic acids. Hydroxybenzoic acids include gallic, p-hydroxybenzoic, protocatechuic, vanillic, and syringic acids, which in common have the C6-C1 structure. Hydroxycinnamic acids are aromatic compounds with a three-carbon side chain (C6-C3), with caffeic, ferulic, p-coumaric, and sinapic acids. The main reported sources of phenolic acids were blueberry, cranberry, pear, cherry (sweet), apple, orange, grapefruit, cherry juice, apple juice, lemon, peach, potato, lettuce, spinach, coffee beans, tea, coffee, and cider. Hydroxycinnamic acids are a major class within the phenolic compounds [3].
Antioxidant defuses free radicals which are powerful reactive intermediates originated from diverse oxidation reactions. Mode of free radical's action results in premature aging, reduced immune function, inflammation, and ultimately into degenerative diseases. Nearly, 85 diseases such as heart diseases, cancer, arthritis, cataracts, and emphysema have been connected to free radicals in the cells. Metal ions decompose lipid hydroperoxide through the hemolytic cleavage of the O-O bond and yield lipid alkoxyl radicals, which trigger free radical chain oxidation. Phenolics block lipid peroxidation by entrapping the lipid alkoxyl radical. This activity is related with the structure of phenols, and the number and position of the $\mathrm{OH}$ group in the molecules [4]. Abdille et al. [5) showed that phenolics are able to alter kinetics of peroxidation by modifying the lipid molecules. They stabilize membranes by decreasing membrane fluidity and inhibit the diffusion of free radicals and limit peroxidative reaction [6-8]. According to Verstraeten et al. [9], the protein-binding capacity of flavanols and procyanidins can interact with membrane phospholipids through hydrogen bonding to the polar head groups of phospholipids. As a consequence, these molecules aggregates at the membranes outside and inside in the cells, thus preventing the access of deleterious molecules to the hydrophobic region of the bilayer including those that can affect membrane structure and those that induce oxidative damage to the membrane components.

Antioxidants in biological systems have multiple functions, including defending against oxidative damage and also as signaling pathway of cells. Although several synthetic antioxidants are available commercially, their use is now restricted due to their side effects [10]. Therefore, demand has been developed to search natural and safe antioxidative agents from plants which are considered as a source of bioactive nutraceutical compounds and are characterized by a broad spectrum of biological activities. Free radical scavenging by antioxidants protects 
cells from damages caused by uncontrolled production of reactive oxygen species and subsequent lipid peroxidation, protein damage and DNA strand breaking [11].

Tectona grandis L f. of Lamiaceae is one of the durable timber wood species in the world. Timber value of teak has been well known from decades and is indigenous to tropical and subtropical countries. Teak possesses many constituents and was reported in folklore medicines. For example, in traditional medicine, the wood powder paste has been used against headache and swellings. Teak was also used for treating inflammation swelling. The leaves of teak showed many pharmacological potentialities such as antibacterial, anticancerous, and antioxidant properties [12].

The present study aims in comparison of phenolic acids and its antioxidant potentialities of young and mature leaf extract of T. grandis L f.

\section{METHODS}

\section{Plant material}

For the present study, fresh young and mature leaves were collected from the natural habitat of Nilambur, Kerala, and the voucher specimen was deposited in the herbarium of University College, Trivandrum (UCB 1208).

\section{Plant sample extraction}

The dried leaf powder (100 g) was extracted with methanol using Soxhlet hot continuous extraction method. The extract was evaporated to dryness using rotary vacuum unit. The final residue thus obtained was subjected to further analysis.

\section{Fourier transform infrared spectroscopy (FTIR) analysis}

The dried extracted samples of young and mature leaves of teak (10 mg) were mixed with $100 \mathrm{mg}$ of dried potassium bromide $(\mathrm{KBr})$ and compressed to prepare as a salt disc. The disc was then read spectrophotometrically (Bio-Rad FTIR-40-model, USA). The frequencies of different components present in each sample were analyzed.

\section{Reversed-phase high-performance liquid chromatography (RP-} HPLC) analysis

HPLC system (Water associates) equipped with a 7725 Rheodyne injector and Waters HPLC pump, 486 tunable absorbance detector and Millennium 2010 software data module was used for the study. A reverse phase HPLC column (4.6 $250 \mathrm{~mm}$ ) was used for the fractionation of phenolic acids. Potassium hydrogen phosphate (75): Acetonitrile (25) was used as the mobile phase for the isocratic elution. An elution period of $20 \mathrm{~min}$ with a flow rate of $0.8 \mathrm{ml} / \mathrm{min}$ was given. Experimental of $10 \mu \mathrm{l}$ sample was loaded and the OD was read at $254 \mathrm{~nm}$. Standard Phenolic acids such as were injected into the column separately. For the identification and quantification of phenolic gallic, vanillic, p-hydroxybenzoic, ferulic, chlorogenic, sinapic, p-coumarate, and cinnamic acids in the extracts following parameters are used such as retention time of the standard, area, and height of the peaks, respectively.

\section{Determination of total phenolic content (TPC)}

TPC was estimated as gallic acid equivalent (GAE) according to the Folin-Ciocalteu reagent. The absorbance was read at $750 \mathrm{~nm}$. TPC was expressed as $\mathrm{mg} / \mathrm{g}$ GAE.

\section{Antioxidant analysis of anthocyanin \\ 2,2-diphenyl-1-picrylhydrazyl (DPPH) free radical scavenging activity}

The free radical scavenging activity was followed by the DPPH method described by Blois [13]. The absorbance was measured at $517 \mathrm{~nm}$. A blank was prepared without adding extract. Lower the absorbance of the reaction mixture indicates higher free radical scavenging activity. BHT was used as a standard.
Ferric reducing/antioxidant power (FRAP) assay

The ferric reducing antioxidant power assay procedure described by Benzie and Strain [14]. The principle of this method is based on the reduction of a ferric-tripyridyltriazine complex to its ferrous colored form in the presence of antioxidants. The absorbance of the reaction mixture was measured at $593 \mathrm{~nm}$ after incubation at $37^{\circ} \mathrm{C}$ for $10 \mathrm{~min}$. The values are expressed as the concentration of antioxidants having a ferric reducing ability equivalent to that of $1 \mathrm{mmol} / \mathrm{L} \mathrm{FeSO}_{4}$.

\section{Metal chelating activity}

The chelation of ferrous ions by extracts was estimated by the method of Dinis et al. [15]. The percentage inhibition of ferrozine - $\mathrm{Fe} 2+$ complex formation was calculated as [(A0-As)/As] $]^{*} 100 . \mathrm{Na}_{2}$ EDTA was used as positive control.

\section{Statistical analysis}

All data were reported as the mean \pm standard deviation of 12 replicates. The data were analyzed using one-way variance analysis (One-Way ANOVA). All statistical analysis was performed using the SPSS 10.0 software package.

\section{RESULTS}

\section{FTIR spectral analysis}

The FTIR analysis of the young and mature leaf ethanolic extracts was performed to unravel their functional groups. The FTIR spectrum of young leaves showed 10 peaks of wavelength ranging from 33012.12 to $588.29 \mathrm{~cm}^{-1}$. Meanwhile, mature leaves showed 11 peaks of wavelength ranging from 3288.63 to $596.00 \mathrm{~cm}^{-1}$ (Figs. 1 and 2 and Tables 1 and 2). The bands between the wave numbers of $1800-750 \mathrm{~cm}^{-1}$ reflected the biochemical composition as the moieties of carbohydrates, lipid, protein secondary structure, and polyphenols in plants. The distinctive peak at the wave number $1462.25 \mathrm{~cm}^{-1}$ in young leaf and $1600.92 \mathrm{~cm}^{-1}$ in mature leaf is assigned to ring C-C stretch of phenyl [16], which reveals the high levels of polyphenolic compounds in the leaves of Tectona grandis. The C-H stretching vibration of the alkanes in the young and mature leaves was represented by the distinctive peaks at wave number $2926.01 \mathrm{~cm}^{-1}$ and $2935.66 \mathrm{~cm}^{-1}$, respectively. The presence of amide

Table 1: FTIR spectral analysis of young methanolic leaf extract of $T$. grandis $\mathrm{L} f$

\begin{tabular}{lll}
\hline Peaks & Functional groups & Bond \\
\hline 3302.12 & Alcohol & O-H stretch \\
3284.77 & Amide & N-H symmetric \\
3267.41 & Amide & N-H symmetric \\
2926.01 & Alkanes & C-H stretch \\
1732.08 & Aldehydes & C=O stretch \\
1598.99 & Amide & N-H bend \\
1402.25 & Aromatic compounds & Ring C=C stretch \\
1263.37 & Esters & O=C=OC stretch \\
1041.56 & Alcohols & O-H stretch \\
\hline
\end{tabular}

FTIR: Fourier transform infrared, T. grandis: Tectona grandis

Table 2: FTIR spectral analysis of mature methanolic leaf extract of T. grandis

\begin{tabular}{lll}
\hline Peaks & Functional groups & Bond \\
\hline 3288.63 & Alcohol & O-H stretch \\
2935.66 & Alkanes & C-H stretch \\
1699.29 & Carboxylic acid & C=O stretch \\
1600.92 & Aromatic compounds & Ring C=C stretch \\
1448.54 & Alkanes & C-H bend \\
1371.39 & Alkyl & CH ${ }^{3}-\mathrm{C}-\mathrm{H}$ bend \\
1265.30 & Ethers & $=\mathrm{C}-\mathrm{O}-\mathrm{C}$ symmetric \\
1043.49 & Alkyl halides & $\mathrm{C}-\mathrm{F}$ stretch \\
835.18 & Aromatic compounds & $\mathrm{C}-\mathrm{H}$ bend \\
709.80 & alkenes & $=\mathrm{C}-\mathrm{H}$ bend \\
\hline FTIR: Fourier transform infrared, $T$ grandis: Tectona grandis
\end{tabular}




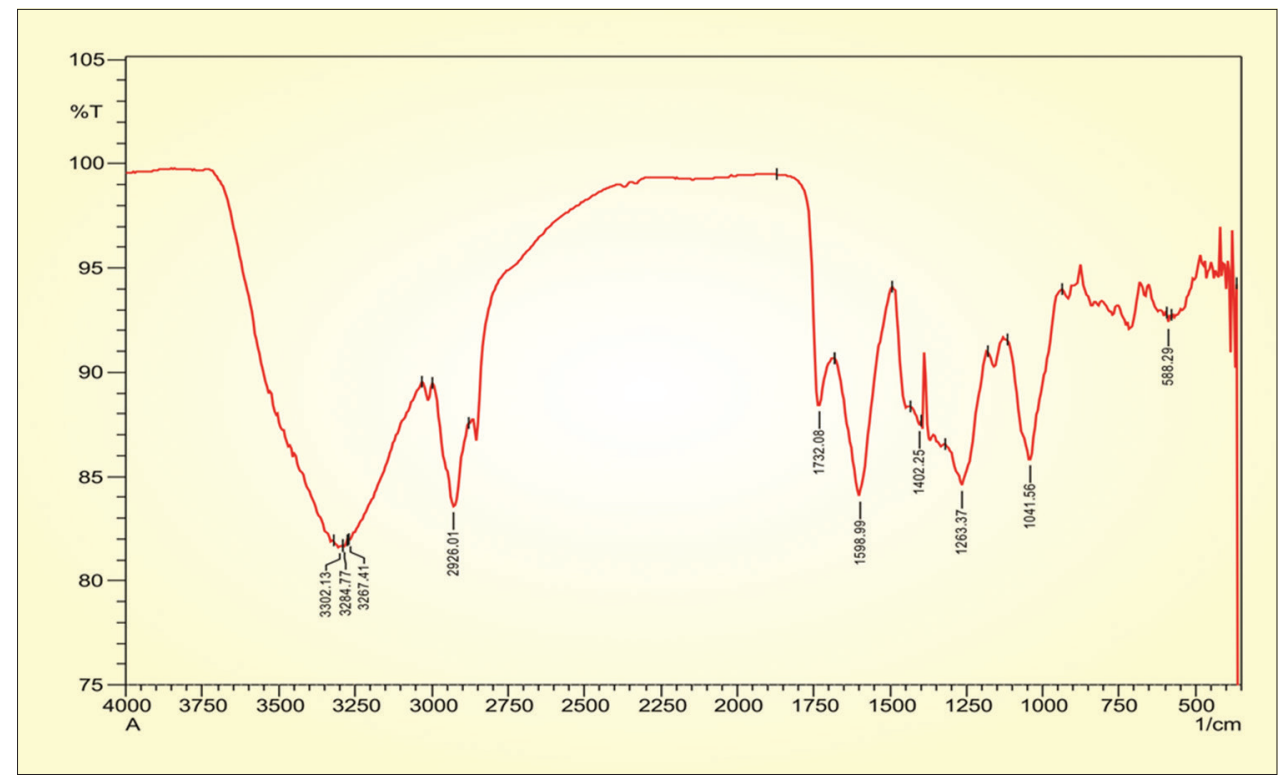

Fig. 1: Fourier transform infrared spectrum of young methanolic leaf extract of Tectona grandis $\mathrm{L} f$

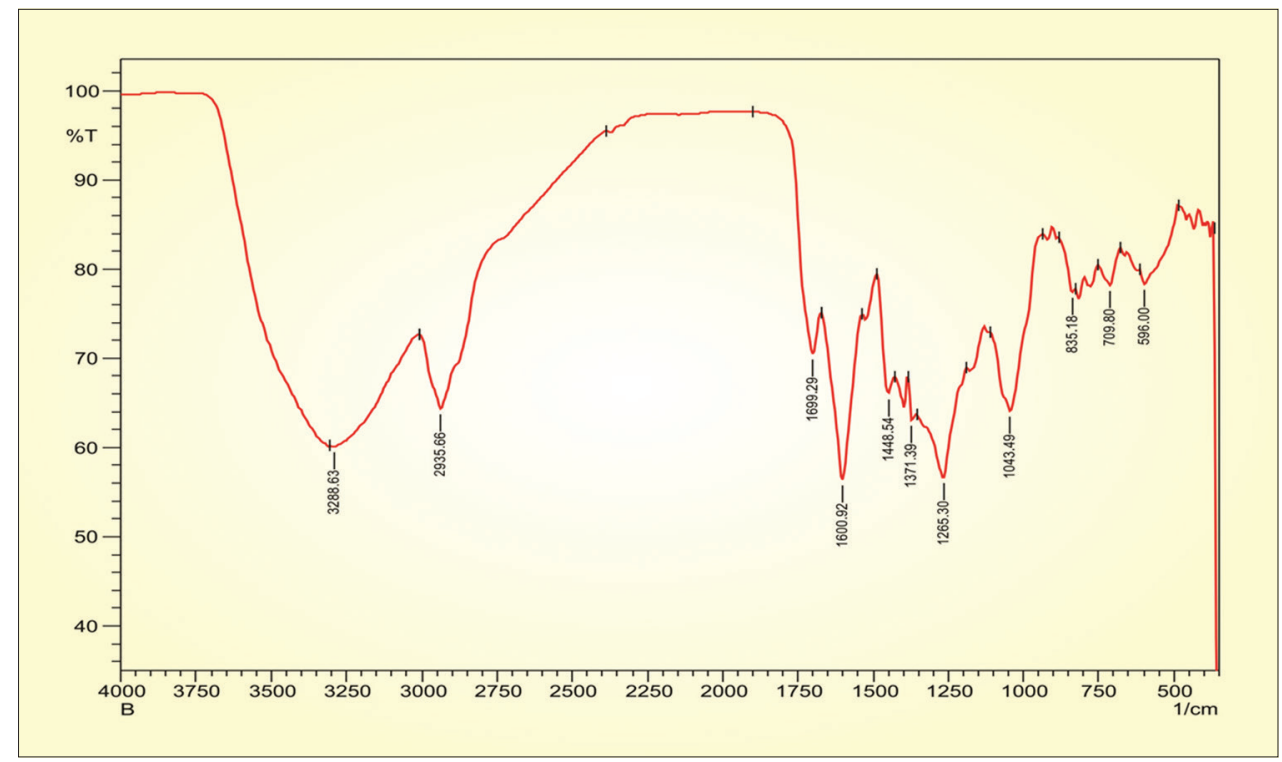

Fig. 2: Fourier transform infrared spectrum of mature methanolic leaf extract of Tectona grandis

groups was only restricted to the young leaf extracts, and they were shown in three different spectral regions of $3284.77 \mathrm{~cm}^{-1}, 3267.41 \mathrm{~cm}^{-1}$, and $1732.08 \mathrm{~cm}^{-1}$. Of these, the peak at $1732.08 \mathrm{~cm}^{-1}$ can be seen as a sharp peak in the spectrum. The minor band at $1402.25 \mathrm{~cm}^{-1}$ in young leaves extract and a major band at $1600.92 \mathrm{~cm}^{-1}$ in the mature leaves extract showed the presence of aromatic compounds.

TPC

The TPC of the young and mature teak leaves extracts were expressed in terms of GAE. It showed a value of $30.28 \mathrm{mg} \mathrm{GAE} / \mathrm{g}$ in mature leaves extract meanwhile, $46.12 \mathrm{mg} \mathrm{GAE} / \mathrm{g}$ in young leaves extract, i.e. the level of TPC is higher in young leaves extract than the mature leaves and the amounts of these compounds may reflect differential antioxidant activities of the teak leaves extracts.

\section{RP-HPLC analysis}

The RP-HPLC analysis of the young leaves extract of teak showed numerous peaks of which only 10 were identified using the retention time and area of the peaks of the internal available standards
(Fig. 3 and Table 3). However, the number peaks obtained with mature leaves extract were less when compared with the young leaves extract, i.e. 8 phenolic acids were identified and quantified (Fig. 4 and Table 4). Of the 10 phenolic acids quantified from the young leaves, sinapic acid, chlorogenic acid, cinnamic acid, and gallic acid were present in a higher amount than the remaining phenolic acids. Similar results were also obtained from the mature leaves extract, i.e. the above referred four phenolic acids showed its prominence in the extract than the others.

\section{Antioxidant activity}

\section{DPPH scavenging assay}

DPPH is a stable free radical with a characteristic absorption, which decreases significantly on exposure to proton radical scavengers [17]. As a rapid and simple measure of antioxidant activity, DPPH radical scavenging capacity is widely used. The assay was based on the reduction of stable radical DPPH to yellow colored diphenyl picrylhydrazine in the presence of a hydrogen donor [18]. In this study, the antioxidant activity of the two leaf extracts were determined by DPPH assay and the results were presented in Table 5. Both the leaves extract showed a dose-dependent 


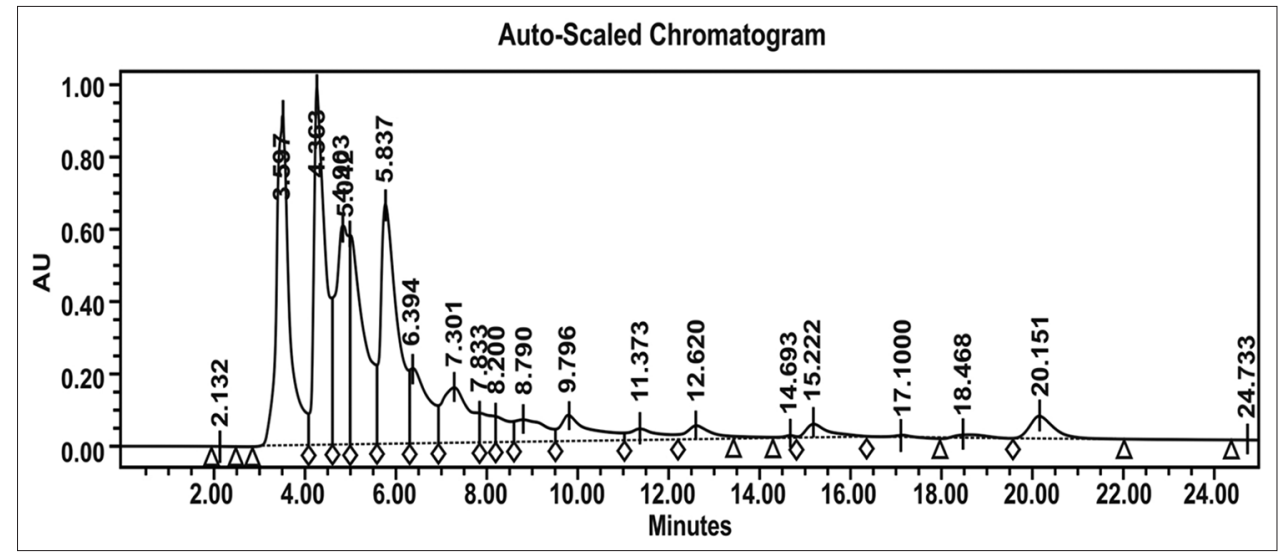

Fig. 3: Reversed-phase high-performance liquid chromatography profile showing various phenolic acids present in the young methanolic leaf extract of Tectona grandis

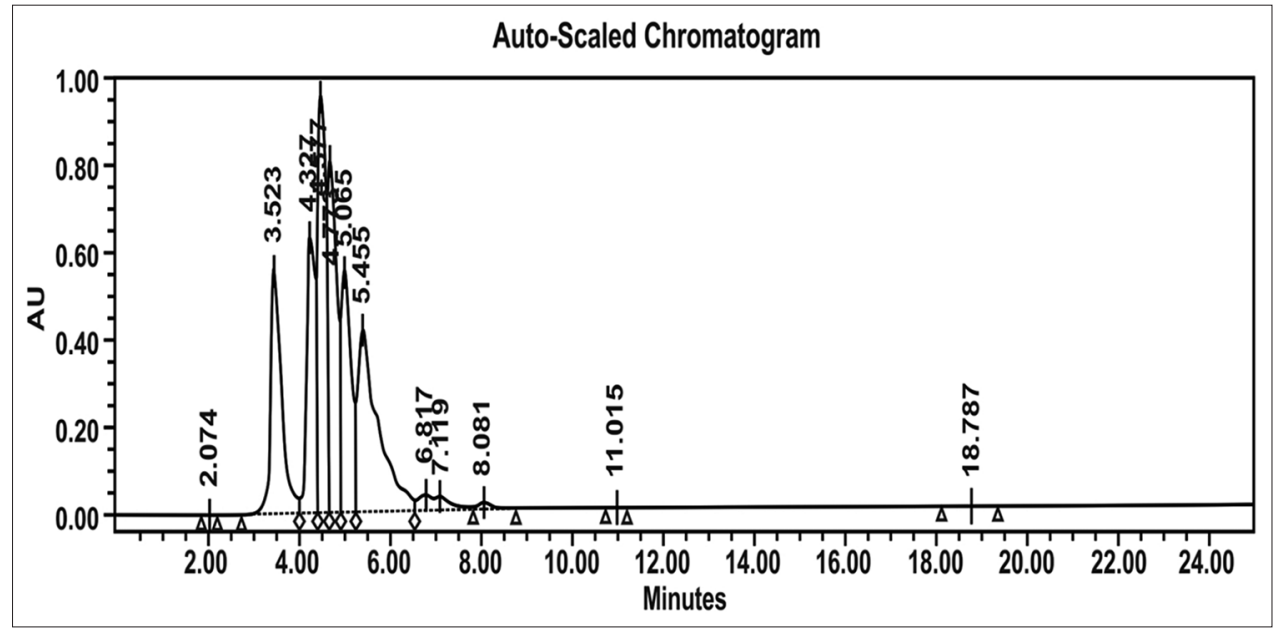

Fig 4: Reversed-phase high-performance liquid chromatography profile showing various phenolic acids present in the mature methanolic leaf extract of Tectona grandis

Table 3: Quantification of various phenolic acids from the young methanolic leaf extract of $T$. grandis by RP-HPLC analysis

\begin{tabular}{ll}
\hline Phenolic acids & Quantity (mg/g) \\
\hline Sinapic acid & 62.7 \\
Phloroglucinol & 26.8 \\
Chlorogenic acid & 64.78 \\
Catechol & 7.79 \\
Ferulic acid & 20.27 \\
Vanillic acid & 6.56 \\
Cinnamic acid & 64.55 \\
Gallic acid & 60.68 \\
Coumaric acid & 8.1 \\
HBA & 1.64 \\
\hline
\end{tabular}

RP-HPLC: Reversed-phase high-performance liquid chromatography,

T. grandis: Tectona grandis

scavenging activity, and the values ranged from $15.9 \pm 0.2 \%-59.2 \pm 1.3 \%$ to $9.6 \pm 1.0 \%-49.8 \pm 1.9 \%$ for young and mature leaf extracts, respectively. The ability of DPPH scavenging by the extracts was comparable with the standard antioxidant BHT, as it showed a percentage of scavenging of $80.05 \%$ at $25 \mu \mathrm{g} / \mathrm{ml}$. On comparison of the antioxidant ability of young and mature leaves, it is clear that young leaves extract showed significant scavenging activity than the mature leaf extract.

\section{FRAP assay}

This assay is often used to measure the antioxidant capacity of foods, beverages, and nutritional supplements containing polyphenols. The
Table 4: Quantification of various phenolic acids from the mature methanolic leaf extract of $T$. grandis by RP-HPLC analysis

\begin{tabular}{ll}
\hline Phenolic acids & Quantity (mg/g) \\
\hline Sinapic acid & 38.6 \\
Phloroglucinol & 15.59 \\
Chlorogenic acid & 44.97 \\
Catechol & 5.41 \\
Vanillic acid & 3.57 \\
Cinnamic acid & 42.19 \\
Gallic acid & 36.08 \\
HBA & 0.54 \\
\hline RP-HPLC: Reversed-phase high-performance liquid chromatography, \\
T. grandis: Tectona grandis
\end{tabular}

FRAP assay may offer a putative index of antioxidant activity and measure the ability of antioxidants to reduce the ferric 2,4,6-tripyridyl$\mathrm{S}$-triazine complex to intensely blue colored ferrous complex in acidic medium. Analysis of the antioxidant power according to the FRAP assay showed that the young leaf extract $(360 \pm 3.8 \mu \mathrm{M} / \mathrm{g}$ sample DW) was more efficient as an antioxidant than the mature leaf extract $(258 \pm 3.4$ $\mu \mathrm{M} / \mathrm{g}$ sample DW) at a concentration of $30 \mu \mathrm{g} / \mathrm{ml}$ sample (Table 6).

Metal chelating activity

Transition metal ions, especially iron can stimulate lipid peroxidation by Fenton reaction and can accelerate lipid peroxidation by decomposing lipid hydroperoxides into peroxyl and alkoxyl radicals that can perpetuate the chain reaction. Metal ion chelating capacity is 
significant since it reduces the concentration of the transition metal that catalyzes lipid peroxidation. Ferrozine can quantitatively chelate with $\mathrm{Fe}^{2+}$ and form a red colored complex. This reaction is limited in the presence of other chelating agents and results in a decrease of the red color of the ferrozine- $\mathrm{Fe}^{2+}$ complex. Measurement of the color reduction estimates the chelating activity to compete with ferrozine for the ferrous ions [19]. The antioxidants present in plant extract forms a coordinate complex with the metal ions (chelating activity) and inhibit the transfer of electrons. Thus, oxidation reaction is arrested, and no free radicals are produced. In this study, the young leaf extract showed a high tendency to forming a coordinate complex with $\mathrm{Fe}^{2+}$ than the mature leaf extract and the percentage of inhibition of ferrozine- $\mathrm{Fe}^{2+}$ complex showed a concentration-dependent manner and can be compared with the synthetic chelating agent EDTA (Table 7).

\section{DISCUSSION}

Recently, there has been an increasing search for new metabolites from plants since they endowed with many pharmacodynamics properties. Polyphenols are secondary metabolites of plants and are generally involved in defense against ultraviolet radiation or pathogen invasion. Toward the end of $24^{\text {th }}$ century, the epidemiological studies

Table 5: Percentage of DPPH radical scavenging of young and mature methanolic leaf extract with various concentrations

\begin{tabular}{lll}
\hline Concentration of sample $(\boldsymbol{\mu g} / \mathbf{m l})$ & \multicolumn{2}{l}{ Percentage of scavenging } \\
\cline { 2 - 3 } & Young & Mature \\
\hline 5 & $15.9 \pm 0.2$ & $9.6 \pm 1.0$ \\
10 & $38.6 \pm 0.44$ & $24.2 \pm 0.8$ \\
15 & $46.8 \pm 0.62$ & $35.3 \pm 0.65$ \\
20 & $55.4 \pm 0.79$ & $42.8 \pm 0.28$ \\
25 & $59.2 \pm 1.3$ & $49.8 \pm 1.9$ \\
BHT (25) & 80.05 & \\
\hline
\end{tabular}

DPPH: 2,2-diphenyl-1-picrylhydrazyl

Table 6: Ferric reducing ability of young and mature methanolic leaf extract with various concentrations and the values are in terms of $\mu \mathrm{M} / \mathrm{g}$ sample (DW)

\begin{tabular}{lll}
\hline Concentration of sample $(\boldsymbol{\mu g} / \mathbf{m l})$ & \multicolumn{2}{l}{$\boldsymbol{\mu M} / \mathbf{g}$ sample (DW) } \\
\cline { 2 - 3 } & Young & Mature \\
\hline 5 & $54 \pm 1.3$ & $33 \pm 0.84$ \\
10 & $98.6 \pm 5.6$ & $65 \pm 1.3$ \\
15 & $149 \pm 2.8$ & $112 \pm 0.89$ \\
20 & $258 \pm 4.6$ & $165 \pm 1.6$ \\
25 & $312 \pm 5.1$ & $216 \pm 2.5$ \\
30 & $360 \pm 3.8$ & $258 \pm 3.4$ \\
BHT $(30)$ & $512.6 \pm 2.5$ & \\
\hline
\end{tabular}

Table 7: Percentage of inhibition of ferrozine-iron complex formation by the young and mature methanolic leaf extract with various concentrations

\begin{tabular}{lll}
\hline Concentration of sample $(\boldsymbol{\mu g} / \mathbf{m l})$ & \multicolumn{2}{l}{$\begin{array}{l}\text { Percentage of } \\
\text { inhibition }\end{array}$} \\
\cline { 2 - 3 } & Young & Mature \\
\hline 5 & $15 \pm 1.3$ & $9.6 \pm 0.72$ \\
10 & $23 \pm 0.65$ & $15.4 \pm 1.3$ \\
15 & $35 \pm 0.98$ & $25.2 \pm 1.7$ \\
20 & $42 \pm 1.3$ & $33.6 \pm 2.2$ \\
25 & $49 \pm 3.5$ & $29.5 \pm 2.7$ \\
30 & $53 \pm 2.6$ & $42.8 \pm 5.4$ \\
EDTA (30) & $60.5 \pm 1.9$ & \\
\hline
\end{tabular}

and associated meta-analyses strongly suggested that long-term consumption of diets rich in plant polyphenols offered protection against the development of cancers, cardiovascular diseases, and diabetes, osteoporosis, and neurodegenerative diseases. Polyphenols and other food phenolics is the subject of increasing scientific interest because of their possible beneficial effects on human health.

Consumption of polyphenol-rich food items enhanced antioxidant status, reduced oxidative DNA damage and stimulated immune cell functions [20]. Many reports have been documented about the antioxidant activity anthocyanin profiles of many fruits and flowers [21,22]. Joni et al. [23) reported that the microwave-assisted extraction significantly resulted higher antioxidant properties in teak leaves in a shorter time compared to the Soxhlet extraction. The literature review of the plant revealed the presence of various phytoconstituents which were responsible for the different activities.

The present study focuses on the comparison of antioxidant potentiality and phenolic content of the young and mature leaf extracts of teak. The study revealed that the teak leaves contains a pool of phenolic compounds identified by RP-HPLC analysis and these were further substantiated with the presence of respective functional groups which are the integral part of these compounds. Similarly, chlorogenic acid is an important intermediate in lignin biosynthesis and was reported to be a chemical sensitizer responsible for human respiratory allergy against certain types of plant materials [24]. Review articles report modest blood pressure lowering effects from chlorogenic acid administration [25]. Interestingly, cinnamic acid is a precursor to the sweetener aspartame via enzyme-catalyzed amination to phenylalanine and its major use in the manufacturing of the methyl, ethyl, and benzyl esters for the perfume industry. In basic research, gallic acid extracted from grape seeds has been shown to inhibit the formation of amyloid fibrils, one of the potential causes of Alzheimer's disease and Parkinson's disease [26]. Liu et al. [27] indicated that gallic acid has its effect on amyloid protein formation by modifying the properties of alpha-synuclein, a protein associated with the onset of neurodegenerative diseases.

Many plant species contain phytoconstituents such as phenols, flavonoids, and tannins which could be responsible for the antioxidant activity through scavenging free radicals or ROSs [28]. Interestingly, in this study, the antioxidant activity of the leaf extracts could be due to the presence of phenolic compounds. It has been reported that the antioxidant activity of many phytocompounds is proportional to their phenolics content suggesting a causative relationship between TPC and antioxidant activity. There are many methods to determine antioxidant capacity, and they differ in terms of their assay principles and experimental conditions. Interestingly, the young leaf extract which exhibited the highest content of total phenolic registered the highest DPPH radical scavenging potential. Oktay et al. [29] also proved the relationship between total phenols and antioxidant activity and this appears to be trend in many plant species. It has been reported that the FRAP assay of Kei apple fruit juice correlated well with the polyphenol concentrations and suggested that higher antioxidant activity of fruit juice might be due to the presence of phenolics [30]. As the consequences of the imbalance in the human antioxidant status, the oxidative stress was increasing which contributes to the emergence of chronic diseases [31]. In recent years, many studies have demonstrated that free radicals are leading to cause of many degenerative diseases and phenolics have attracted increasing attention for their antioxidant activities. These antioxidants work through singlet and triplet oxygen quenchers, free radical scavengers, peroxide decomposers, and enzyme inhibitors.

Marginal data have been available related with teak such as ethanolic extract of bark $[32,33]$ and methanolic extract of root for the treatment of diabetes mellitus [34]. In spite of the above activities leaves of the plant also possess analgesic and antioxidant activity [35]. 
Phenols reduce the rates of oxidation of organic matter by transferring $\mathrm{H}$ atom of their $\mathrm{OH}$ groups to the chain-carrying $\mathrm{ROO}^{*}$ radicals, i.e., a concerted transfer of the hydrogen as a proton and of one electron between the two oxygen atoms, $\mathrm{O}-\mathrm{H}---\mathrm{O}^{*}$ (protoncoupled electron transfer mechanism). The antioxidant capabilities of phenols are strongly reduced by hydrogen-bond accepting solvents since the hydrogen-bonded molecules $\mathrm{OH}---\mathrm{S}$ are virtually unreactive toward ROO* radicals. The magnitude of these kinetic solvent effects is determined by the solute acidity alpha $(2)(\mathrm{H})$ of $\mathrm{OH}$ (range $0-1$ ) and solvent basicity beta $(2)(\mathrm{H})($ range $0-1$ ). Hydroxyl solvents (alcohols) have a double effect on $\mathrm{OH}$. On the one hand, they act as hydrogen-bond accepting solvents and reduce the conventional rates of the $\mathrm{OH}+\mathrm{ROO}^{*}$ reaction. On the other hand, these solvents favor the ionization of $\mathrm{OH}$ into their phenoxide anions $\mathrm{O}(-)$, which may react with ROO* very rapidly by electron transfer (sequential proton loss electron transfer mechanism). The overall effect is, therefore, determined by the ionization degree of $\mathrm{OH}$ [36]. Pereira et al. [37) also reported the chemistry of phenols with their biological activity.

Hossain and Shah [38) studied the total phenols content and antioxidant activity of essential oil and different solvent extracts of endemic plant Merremia borneensis. Michalak [39] related phenolics with their antioxidant activity in plants growing under heavy metal stress. Deighton et al. [4] and Abdille et al. [5] reported close relationship between TPC and antioxidative activity of the fruits, plants, and vegetables. The chemical composition and chemical structures of active extract components are important factors governing the efficacy of natural antioxidants and the antioxidant activity of an extract but also needs their characterization. For instance, it has already been reported that phenolic compounds with ortho- and para-dihydroxylation or a hydroxy and a methoxy group or both are more effective than simple phenolics [40]. Maryam et al. scientifically validate the traditional uses of many medicinal plants and also correlate the antioxidant activity with their phenolic contents [41]. A similar study was also reported in Boerhavia diffusa by Richa et al. and found that there is a significant correlation between the antioxidant activities and total phenol, flavonoids, and ascorbic acid contents [42].

\section{CONCLUSION}

The present study concludes that the methanolic extract of the teak leaf are rich source of many phenolic compounds and these compounds attribute to the antioxidant capacity of the leaves. Meanwhile, by comparing the young and mature leaves, the young leaves showed much more potential than the other. It is, therefore, concluded that the young teak leaves can be used as a good source of natural antioxidant. Further, works are warranted to isolate and characterize the leading component from the leaves.

\section{ACKNOWLEGDEMENTS}

The authors thank the Kerala State Council for Science, Environment and Technology, Govt. of Kerala and UGC, for providing financial support for the completion of the work.

\section{REFERENCES}

1. Cavaiuolo M, Cocetta G, Ferrante A. The antioxidants changes in ornamental flowers during development and senescence. Antioxidants (Basel)2013;2:132-55.

2. Genskowsky E, Puente LA, Pérez-Álvarez JA, Fernández-López J, Muñoz LA, Viuda-Martos M. Determination of polyphenolic profile, antioxidant activity and antibacterial properties of maqui [Aristotelia chilensis (Molina) Stuntz] a Chilean blackberry. J Sci Food Agric 2016;96:4235-42.

3. Ozcan T, Akpinar-Bayizit A, Yilmaz-Ersan L, Delikanli B. Phenolics in human health. Int J Chem Eng Appl 2014;5:393-6.

4. Deighton N, Brennan R, Finn C, Davies HV. Antioxidant properties of domesticated and wild Rubus species. J Sci Food Agric 2000;80:1307-131.
5. Abdille MH, Singh RP, Jayaprakasha GK, Jena BS. Antioxidant activity of the extracts from Dillenia indica fruits. Food Chem 2005;90:891-6.

6. Misiti F, Castagnola M, Zuppi C, Giardina B, Messana I. Role of ergothioneine on S-nitrosoglutathione catabolism. Biochem J 2001;356:799-804

7. Arora A, Byrem TM, Nair MG, Strasburg GM. Modulation of liposomal membrane fluidity by flavonoids and isoflavonoids. Arch Biochem Biophys 2000;373:102-9.

8. Blokhina O, Virolainen E, Fagerstedt KV. Antioxidants, oxidative damage and oxygen deprivation stress: a review. Ann Bot 2003;91:179-94.

9. Verstraeten SV, Keen CL, Schmitz HH, Fraga CG, Oteiza PI. Flavan3 -ols and procyanidins protect liposomes against lipid oxidation and disruption of the bilayer structure. Free Radic Biol Med 2003;34:84-92.

10. Selvaraju M, Shanmugam U, Muthuvel A, Thangavel B. In vitro antioxidant properties and FTIR analysis of two seaweeds of Gulf of Mannar. Asian Pac J Trop Biomed 2012;1:66-70.

11. Panat NA, Maurya DK, Ghaskadbi SS, Sandur SK. Troxerutin, a plant flavonoid, protects cells against oxidative stress-induced cell death through radical scavenging mechanism. Food Chem 2016;194:32-45.

12. Mahesh SK, Jayakumaran NA. Antibacterial, cytotoxic and antioxidant potential of different extracts from leaf, bark and wood of Tectona grandis. Int J Pharma Sci Drug Res 2010;2:155-8.

13. Blois MS. Antioxidant determinations by the use of a stable free radical. Nature 1958;29:1199-200.

14. Benzie IF, Strain JJ. The ferric reducing ability of plasma (FRAP) as a measure of "antioxidant power": the FRAP assay. Anal Biochem 1996;239:70-6.

15. Dinis TC, Madeira VM, Almeida ML. Action of phenolic derivates (acetoaminophen, salycilate and 5-aminosalycilate) as inhibitors of membrane lipid peroxidation and as peroxyl radical scavengers. Arch Biochem Biophys 1994;315:161-9.

16. Schulz H, Baranska M. Identification and quantification of valuable plant substance by IR and Raman spectroscopy. Vib Spectrosc 2007;42:13-25.

17. Sun Q, Shen H, Luo Y. Antioxidant activity of hydrolysates and peptide fractions derived from porcine hemoglobin. J Food Sci Technol 2011;48:53-60.

18. Longanayaki N, Manian S. In vitro antioxidant properties of indigenous underutilized fruits. Food Sci Biotech 2010;19:724-34.

19. Soler-Rivas C, Espin JC, Wichers HJ. An easy and fast test to compare total free radical scavenger capacity of foodstuffs. Phytochem Anal 2000;11:330-8.

20. Bub A, Watzl B, Blockhaus M, Briviba K, Liegibel U, Müller H, et al. Fruit juice consumption modulates antioxidative status, immune status and DNA damage. J Nutr Biochem 2003;14:90-8.

21. Nakajima JI, Tanaka I, Seo S, Yamazaki M, Saito K. LC/PDA/ESI-MS profiling and radical scavenging activity of anthocyanins in various berries. J Biomed Biotechnol 2004;2004:241-7.

22. Benevenuti S, Pellati F, Melegari M, Bertelli D. Polyphenols, anthocyanins, ascorbic acid and radical scavenging activity of Rubus, Ribes and Aronia. J Food Sci 2004;69:164-9.

23. Joni K, Estri LA, Dian WN, Elina CS. Antioxidant activity of MAE extracted teak (Tectona grandis L f.) leaves collected from different plantation site at Java Island, Indonesia. 2016;9:154-60.

24. Johnston KL, Clifford MN, Morgan LM. Coffee acely modifies gastrointestinal hormone secretion and galactose tolerance in humans: Glyceine effects of cholorogenic acids and caffeine. Am J Clin Nutr 2003;78:728-33.

25. Gengmao Z, Shihui L, Xing S, Yizhou W, Zipan C. The role of silicon in physiology of the medicinal plant (Lonicera japonica L.) under salt stress. Sci Rep 2015;5:12696.

26. Wang L, Halquist MS, Sweet DH. Simultaneous determination of gallic acid and gentisic acid in organic anion transporter expressing cells by liquid chromatography-tandem mass spectrometry. J Chromatogr B Analyt Technol Biomed Life Sci 2013;937:91-6.

27. Liu Y, Carver JA, Calabrese AN, Pukala TL. Gallic acid interacts with a-synuclein to prevent the structural collapse necessary for its aggregation. Biochim Biophys Acta 2014;1844:1481-5.

28. Athiperumalsamy T, Rajeswari VD, Poorna SH, Kumar V, Jesudas LL. Antioxidant activities of sea grasses and seaweeds. Bot Mar 2010;53:251-7.

29. Oktay M, Culcin I, Kufrevioglu OI. Determination of in vitro antioxidant activity of fennel (Foeniculum vulgarae) seed extracts. Lebensm Technol 2003;36:263-71.

30. Loots DT, van der Westhuizen FH, Jerling J. Polyphenol composition and antioxidant activity of Kei-apple (Dovyalis caffra) juice. J Agric 
Food Chem 2006;54:1271-6.

31. Nadeem A, Raj HG, Chhabra SK. Increased oxidative stress and altered levels of antioxidants in chronic obstructive pulmonary disease. Inflammation 2005;29:23-32.

32. Ghaisas MM, Navghare VV, Takawale AR, Zope VS, Phanse MA. Antidiabetic and nephroprotective effect of Tectona grandis Linn. in alloxan induced diabetes. Ars Pharm 2010;51:195-206.

33. Ghaisas M, Navghare V, Takawale A, Zope V, Tanwar M, Deshpande A. Effect of Tectona grandis Linn. on dexamethasone-induced insulin resistance in mice. J Ethnopharmacol 2009;122:304-7.

34. Verma P, Sharma V, Samanta KC. Hypoglycemic activity of methanolic extract of Tectona grandis Linn. root in alloxan induced diabetic rats. J Appl Pharma Sci 2011;1:106-9.

35. Nayeem N, Karvekar M. Comparative phytochemical and pharmacological screening of the methanolic extracts of the frontal and mature leaves of Tectona grandis. Int J Pharm Biol Sci 2010;1:1-7.

36. Foti MC. Antioxidant properties of phenols. J Pharm Pharmacol
2007:59:1673-85

37. Pereira DM, Valentao P, Pereira JA, Andrad PB. Phenolics: From chemistry to biology. Molecules 2009;14:2202-11.

38. Hossain MA, Shah MD. A study on the total phenols content and antioxidant activity of essential oil and different solvent extracts of endemic plant Merremia borneensis. Arab J Chem 2015;8:66-71.

39. Michalak A. Phenolic compounds and their antioxidant activity in plants growing under heavy metal stress polish. J Environ Stud 2006; 15:523-30.

40. Shahidi F, Naczk M. Food Phenolics: Sources, Chemistry, Effects and Applications. Lancaster, PA: Technomic Publishing Co. Inc.; 2004.

41. Maryam Z, Farrukh A, Iqbal A. The in vitro antioxidant activity and phenolic content of four Indian medicinal plants. Int J Pharm Pharm Sci 2009;1:88-95.

42. Richa B, Ankita Y, Ra S. Phytochemicals and antioxidant activity in Boerhavia diffusa. Int J Pharm Pharm Sci 2014;6:344-8. 